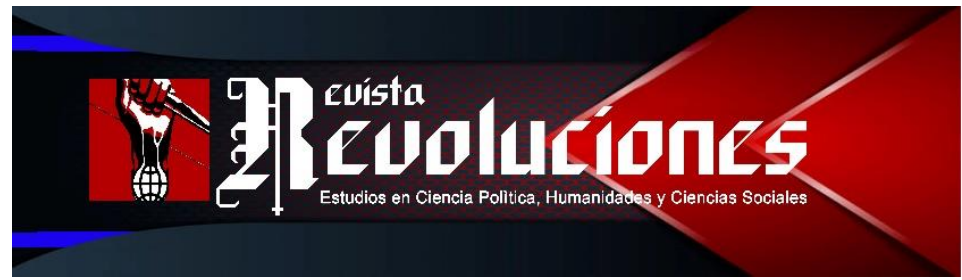

ENSAYO

\title{
"VASALLOS PROPIAMENTE ERAN LOS PLEBEYOS; Y LOS NOBLES REALMENTE SEÑORES”. LA PARTICIPACIÓN POPULAR DURANTE LA INDEPENDENCIA EN EL PERÚ, 1821-1824
}

\section{"Vassals properly were the commoners; and the nobles really lords”. Popular participation during independence in Peru, 1821- 1824}

\author{
Daniel Morán ${ }^{1}$ \\ UNIVERSIDAD NACIONAL MAYOR DE SAN \\ MARCOS \\ PERÚ \\ lmoranr@unmsm.edu.pe \\ https://orcid.org/o0oo-0002-8244- \\ 5390
}

\author{
Miriam Acuña ${ }^{2}$ \\ UNIVERSIDAD CESAR VALLEJO \\ PERÚ \\ macunab@ucv.edu.pe \\ https://orcid.org/oooo- \\ 0003-2599-6978
}

Jesús Yarango3
UNIVERSIDAD NACIONAL MAYOR DE SAN
MARCOS
PERU
jesus.yarango@unmsm.edu.pe
https://orcid.org/oooo-ooo3-

3856-9975

DOI: https://doi.org/10.35622/j.rr.2022.07.005

Recibido: 10-XI-2021 / Aceptado: 10-II-2022 / Actualizado: 10-II-2022

\section{Resumen}

En el año de la conmemoración del Bicentenario de la independencia del Perú, conviene precisar el rol jugado por los sectores populares en la gesta emancipadora, especialmente su activa participación como soldados y oficiales en ambos ejércitos. Pese al papel que cumplieron, la historiografía tradicional no le ha dado el relieve correspondiente. En ese sentido, esta investigación se suma a una serie de trabajos que contribuyen a situar y

\footnotetext{
${ }^{1}$ Docente Investigador de la Dirección de Estudios Generales en la Universidad San Ignacio de Loyola y Docente Auxiliar en la Escuela Profesional de Historia de la Facultad de Ciencias Sociales en la Universidad Nacional Mayor de San Marcos (Perú). Actualmente calificado como Investigador Renacyt (ex-Regina) Grupo Carlos Monge Nivel IV en CONCYTEC- Perú (2019-2021): http://renacyt.concytec.gob.pe/ ReporteRenacyt/investigadorCalificado.zul Doctor en Historia en la Universidad de Buenos Aires (Argentina, 2017), Magíster en Historia en el Instituto de Altos Estudios Sociales de la Universidad Nacional de General San Martín (Argentina, 2012) y Licenciado en Historia en la Universidad Nacional Mayor de San Marcos (Perú, 2008). Entre sus temas de interés están la historia política y cultural de América Latina y la historia de la prensa y los medios de comunicación en los tiempos de la independencia. ${ }^{2}$ Docente universitario con mas de 10 años de experiencia tanto en posgrado como pregrado, dictando cursos de emprendimiento y gestión de la organización.

3 Estudiante de quinto año de Historia en la Universidad Nacional Mayor de San Marcos. Su tema de interés es la historia económica virreinal en Lima a inicios del siglo xix, en el contexto de las guerras contrarrevolucionarias. Es miembro adherente del Grupo de Investigación Historia Económica y Social del ISHRA.
} 
"VASALLOS PROPIAMENTE ERAN LOS PLEBEYOS; Y LOS NOBLES REALMENTE SEÑORES".

LA PARTICIPACIÓN POPULAR DURANTE LA INDEPENDENCIA EN EL PERÚ, 1821-1824

ISSN: 2710-0499 ISSN-L: 2710-0480

esclarecer sus funciones de la llamada plebe, especialmente durante los tiempos de la consolidación de la independencia peruana entre 1821 y 1824.

Palabras Clave: Independencia, sectores populares, soldados, prensa, guerra.

\begin{abstract}
In the year of the commemoration of the Bicentennial of the independence of Peru, it is convenient to specify the role played by the popular sectors in the emancipatory feat, especially their active participation as soldiers and officers in both armies. Despite the role they played, traditional historiography has not given it the corresponding prominence. In this sense, this research adds to a series of works that contribute to locate and clarify their functions of the so-called common people, especially during the times of the consolidation of Peruvian independence between 1821 and 1824.
\end{abstract}

Keyword: Independence, popular sectors, soldiers, press, war.

\title{
INTRODUCCIÓN
}

En el contexto del bicentenario de la independencia del Perú, una serie de investigaciones recientes han permitido ampliar nuestros conocimientos sobre este período desde el campo de la historia política, militar y cultural (Morán y Carcelén, 2018 y 2019) (Chust y Rosas, 2017) (Aljovín y Velázquez, 2017) (O ’Phelan, 2016). A estas dimensiones debemos añadir algunos no tan investigados como la participación de los sectores populares o subalternos, que no solían concitar mucho interés tanto por la historiografía tradicional como por la historiografía reciente.

El objetivo central de esta investigación es identificar y analizar el rol cumplido por los sectores populares durante la consolidación de la independencia del Perú (1821-1824). Aunque esta participación popular se produjo en diferentes momentos del proceso en su conjunto (Morán y Aguirre, 2013), y podemos remontarnos incluso hasta las rebeliones anticoloniales del siglo XVIII, integrando los ejércitos realistas y rebeldes (Marchena, 1992) (O 'Phelan, 2012); ello no es el núcleo de este trabajo. De manera precisa, esta investigación quiere precisar el rol jugado por los sectores populares en la etapa final de la emancipación, en medio de la crisis política que vivía el Perú por no haberse completado la independencia durante la etapa de San Martín y encontrarse en serias dificultades durante la etapa de Bolívar.

En esa perspectiva, la investigación utiliza como fuentes documentales periódicos, relaciones de viajeros, manuscritos e impresos diversos publicados entre los años de 1821 a 1824. Para ello, en primer lugar, analizamos la historiografía sobre los sectores subalternos en el contexto de las guerras de independencia, señalando un nuevo paradigma desarrollado en los últimos años. Posteriormente el trabajo analiza de manera puntual el papel desarrollado por la plebe en estos complejos años, donde coexistía la amenaza militar española y la inestabilidad política en el Perú. 


\section{DESARROLLO}

\section{El nuevo paradigma en el estudio de los sectores populares en la independencia}

La conmemoración del sesquicentenario de la independencia (1971) fue la ocasión para la publicación de un conjunto de fuentes documentales y plantear nuevas líneas de investigación, hipótesis e interpretaciones que cuestionaron la historiografía existente. Esta visión desarrollada durante el siglo XIX y la primera mitad del siglo XX, había priorizado un análisis militar y político sobrevalorando el rol de los grandes personajes como gestores de la historia y como parte de la formación de la conciencia e identidad nacional (Basadre, 1929) (Leguía y Martínez, 1921) (Puente Candamo, 1970) (Porras, 1974). Esta historiografía, aunque sí llegó a señalar el papel del pueblo en la revolución, no desarrollaron un análisis de su rol exacto más allá de lo táctico; y mucho menos indagaron sobre su propia agenda y razones personales, locales o regionales- para su participación política (Rivera Serna, 1958) (Vergara, 1973) (Beltrán, 1977) (Dumbar Temple, 1971-76). La excepción fueron los trabajos de Basadre quien brindó una mirada mucho más moderna como respuesta a los desafíos historiográficos de los años 70 (Basadre, 1973).

Frente al canon historiográfico consagrado también en los textos escolares, surgió el célebre artículo de Heraclio Bonilla y Karen Spalding (1972), donde ponían en tela de juicio a la historiografía tradicional y su visión sobre las guerras de independencia, marcando un punto de inflexión en la historiografía peruana sobre la guerra de independencia. En base a esta publicación se desarrolló la nueva historia en el Perú, punto de partida para una reevaluación de la concepción existente sobre las guerras de independencia, dándole una mayor visibilidad a la participación de los sectores subalternos, aunque señalando sus límites.

Así, a partir de esta nueva historia, para distinguirse de la historia tradicional, se produjeron una serie de trabajos que destacaban el papel clave de los sectores sociales, especialmente negros, pardos y morenos; así como indios y mestizos en las guerras de independencia. Se afirma que los afrodescendientes adoptaron posturas políticas acorde a sus intereses y en procura de obtener beneficios y privilegios que los colocaran por encima de los grupos indígenas (Hunefeldt, 1979a y 1979b) (Flores Galindo, 1987 y 1984). La preeminencia demográfica de los negros en la costa se complementa con el gran porcentaje de indios y mestizos en las zonas andinas, sobre los que Scarlett O 'Phelan ha documentado su participación con amplitud durante las revueltas y rebeliones anticoloniales desarrolladas en el espacio peruano-boliviano durante el siglo XVIII (O’Phelan, 1987).

Estos dos grupos sociales, en esencia, tenían rivalidades y conflictos entre sí. Flores Galindo es categórico al afirmar que las relaciones entre negros e indios fueron irreconciliables y que se enfrentaban constantemente. El gobierno colonial se benefició de esto y por ello alentó estas diferencias de intereses y contraposiciones con el fin de eliminar cualquier posible cohesión que abonará en favor de una insurrección conjunta (1987). En ese sentido, algunos investigadores afirmaron que los movimientos de los sectores populares tenían un carácter 
localista, sin perspectiva nacional; es decir; buscaban sus propios intereses y no un beneficio común sea cono etnia o clase (Flores Galindo, 1983) (Hunefeldt, 1978) (O ‘Phelan, 1987).

Los historiadores han examinado el rol de las regiones en el proceso de independencia, como respuesta a las visiones continentales, sub-continentales, nacionales o limeño-céntricas. Asimismo, se buscaba identificar con mayor precisión la participación de los sectores populares locales o regionales. Desde esta óptica, encontramos los trabajos de Walker (1999 y 2009) y Garret (2009), que han analizado a la nobleza indígena y los indios comunes en el Cuzco; Chambers (2003) y Sánchez (2011) trabajaron la participación popular y miliciana en Arequipa; Thurner (2006), Espinoza (2007), Sala i Vila (1992 y 1996) y Pilco (2021) ahondaron en las intervenciones indias y mestizas en Ancash, Cajamarca y el sur andino, respectivamente; Méndez (1991 y 2005) y Bonilla (2016) discutieron la importancia de la rebelión de los iquichanos; Montoya (2020), Bazán (2017) y Nieto (2004), rescatan la cultura política plebeya en la rebelión de Huánuco; y Espinoza (2014) trabajó una región poco estudiada; Amazonas. Este conjunto de investigaciones nos permite deducir: el rol central activo -político y militar- de la plebe en la revolución, las complejas relaciones entre la elite 'nacional' y los grupos populares, las discrepancias y contradicciones políticas dentro de los grupos subalternos y la recurrencia de los investigadores a los archivos judiciales como fuente para pensar y documentar la participación popular, especialmente las secciones de causas criminales, expedientes judiciales y sumarios militares.

Hoy contamos con una gama variada de fuentes -especialmente escritas- para documentar la participación de los sectores populares regionales en las guerras de independencia y de cómo forjaron sus relaciones con los centros de poder. Sobre el rol de Lima tenemos un mayor número de trabajos como los ya señalados de Flores Galindo y Hunefeldt, a los que se suman Aguirre (1993 y 2005), Arrelucea (2018), Cosamalón (1999), Montoya (2002, 2020), Bonilla (2010 y 2016), Hunefeldt (2010), Morán y Aguirre (2013), Morán (2020), Escanilla (2021), Rojas (2017) y Velásquez (2017). Estos trabajos han evidenciado el rol político de la plebe, su composición heterogénea, las alianzas de intereses y su fragilidad; así como sus divergencias internas. Esta historiografía parte de la premisa de que, en las capitales, especialmente de la costa, la mayor fuerza militar estuvo conformada por la población afrodescendientes y, por el contrario, en los andes existió una preeminencia de tropas indígenas.

Estas investigaciones han permitido replantear el paradigma sobre el estudio de los sectores populares. Para Chust y Serrano, "ha quedado claro que los sectores populares intervinieron y movilizaron bajo una perspectiva, que no era defender alguno de los bandos, ya sea patriótico o realista, sino por interés concretos vinculado a sus grupos y etnias" (2009: 1819). Esta nueva historia, de indios, negros y castas ha permitido una relectura del proceso independentista a partir de sus propios actores.

En esencia, esta nueva historia nos ha brindado una nueva visión sobre los sectores populares: a) la fuerte militarización y politización de los heterogéneos sectores populares; b) la presencia de estos grupos plebeyos como combatientes tanto en las filas patriotas como en las filas realistas; c) la existencia de una fragmentación dentro de los sectores indígenas y 
afrodescendientes locales, e incluso, enfrentamiento de intereses al interior de estos grupos sociales; d) la importancia de los espacios locales y regionales y la función clave de la sociedad rural en la configuración del poder político tanto a nivel local como regional y nacional; debido a la creciente ruralización del poder; y, e) la incorporación de la plebe en las milicias, montoneras o guerrillas como medio para conseguir beneficios, derechos y prerrogativas y satisfacer los intereses de grupo; lo que en no pocas ocasiones se transforma en 'politica armada'.

\section{La plebe en armas en tiempos de la consolidación de la independencia (1821- 1824)}

La guerra de independencia abrió una serie de excusas que permitió institucionalizar la participación de los sectores populares al ser enrolados formalmente a los ejércitos en lucha. E incluso las fuerzas armadas irregulares, como guerrillas y montoneras, también estuvieron en capacidad de obtener una serie de beneficios tangibles, por el temor de que cambiaran de bando. Tanto españoles como patriotas recurrieron a los sectores populares para aumentar sus tropas y defender sus intereses y tuvieron que negociar su fidelidad otorgando beneficios. Las ventajas para ambos bandos eran tangibles: las tropas locales conocían el terreno y podían contribuir con la logística (Flores Galindo, 1983) (Guardino, 1989). Sin embargo, esta heterogeneidad no sólo social, sino también racial, fue un serio obstáculo para su disciplinamiento. Aunque esa heterogeneidad no era acentuada en la población indígena, sino en la población afrodescendiente y las llamadas castas, un producto de la estructuración o desestructuración de las reformar borbónicas.

En este contexto, diversos actores sociales, especialmente la elite española y criolla, produjeron una serie de imágenes y percepciones sobre la plebe, que iban desde el libertinaje hasta el desenfreno; que no dejaban de causar temor social debido a la violencia desatada por la guerra de independencia, violencia que se producía en ambos bandos; y que parecía incontenible en el ámbito rural y que podría ser incontenible en el ámbito urbano por una imaginada alianza entre afrodescendientes libres y esclavos, población que era demográficamente densa en las ciudades. Los relatos de viajeros dan cuenta de esos temores frente a la posibilidad de una ciudad no controlada ni por los españoles ni por los patriotas. La proclamación de la independencia en Lima en 1821 no contribuyó a disuadir los temores. El miedo a los sectores sociales será una constante y la posibilidad de una rebelión de esclavos en la ciudad de Lima como había ocurrido en Haití, caló en el imaginario de la sociedad, aunque no hubiera evidencias tangibles de esa posibilidad. De entre todos los viajeros, de paso por Lima, en aquel entonces, fue Basilio Hall y W. B. Stevenson quienes han dejado testimonio de esta angustia social. Según Hall:

"Esta era la creencia, que la población esclava de la ciudad pensaba aprovechar la ausencia de las tropas para levantarse en masa y masacrar a los blancos. En cuanto a mí, no puedo creer que esto fuese posible; pues los esclavos nunca tuvieron tiempo para tomar tal medida; y sus hábitos no eran de unión y empresa, siendo todos sirvientes y diseminados en una vasta ciudad, con rarísimas ocasiones de trato confidencial" (Núñez, 1971: 226-227). 
El temor y pánico se fundamentaba en el gran porcentaje de población afrodescendiente que residía en Lima, incluyendo negros esclavos y libres. Hall señala que el pánico a esta situación se encontraba extendido en todos los grupos de poder limeño, que en su gran mayoría eran españoles y criollos; aunque él creía que la rebelión era poco probable por las grandes diferencias y divisiones existente entre ellos. De similar parecer era el viajero Camille de Roquefeuil afirmó al respecto: "el pueblo peruano tiene muy poca energía para intentar por sí mismo un gran movimiento capaz de acelerar la cristalización de sus anhelos parece permanecer sumiso, mientras las tropas realistas puedan impedir que las de Buenos Aires penetren en el interior" (Núñez, 1971: 139-140). Esta falta de cohesión y energía no necesariamente tenía que ver solo con la plebe. El viajero francés dentro del concepto pueblo incluyó a todos los vecinos de la capital. Pese al clima político y militar y el estrés social y penurias económicas causadas por la guerra, ello no impedía que la elite limeña dejara de preocuparse por sus intereses, por ello, en palabras de Hall:

"Se escribió una carta breve a San Martín, invitándolo a entrar a la ciudad, para protegerla contra los inminentes peligros que la amenazaba. No era solamente de los esclavos y de la plebe que se tenía miedo, sino, con más razón, de la multitud de indios armados que rodeaban la ciudad, quienes, aunque bajo las órdenes de oficiales de San Martín, eran tropas salvajes e indisciplinadas y podrían entrar a la plaza en masa tan pronto como evacuasen los españoles." (Núñez, 1971: 227-228).

Así, los grupos de poder limeños solicitaron el ingreso de San Martín a la ciudad de Lima no por ser partidarios de la independencia, sino para evitar una revolución de los sectores subalternos que pudiera alterar la estructura de poder y económica que tanto los beneficiaba. El miedo fue un factor relevante en la toma de posiciones políticas independientemente de las convicciones políticas. Según el viajero Alexander Caldcleugh, "las clases inferiores no ganarían nada con el cambio. Libertad y Constitución, términos oídos por primera vez, no les significaba nada. Por tanto, San Martín tenía que efectuar su propósito con las clases más favorecidas" (Núñez, 1971: 194-195).

Para la elite limeña era muy importante que alguien ejerciera la autoridad en Lima -sea realista o patriota- San Martín ingresó a la ciudad para controlar al populacho, evitar una revolución, y negociar con la elite limeña el futuro político del Perú. Pocos después, será Monteagudo quien reclutará a la plebe como milicias urbanas para formar parte de las luchas por la independencia y convertirlos en factor de presión contra la elite que no tenía poderosas razones para dejar de ser realistas de la noche a la mañana.

En este contexto de revolución, afloraron con nitidez una serie de estereotipos sobre la plebe. El general patriota Guillermo Miller, en sus memorias, nos brinda ciertas imágenes sobre los sectores populares. Él describió a los soldados que formaron parte del batallón que dirigió como negros criollos rioplatenses que: "eran dóciles, fáciles de instruir y amantes de sus oficiales: muchos se hacían notar por su natural despejo y limpieza, y casi todos por su buena conducta. Maniobraban perfectamente, y era opinión generalmente recibida que marchaba mejor que los cuerpos formados de blancos" (Miller, 1829: 187). En contraste, el general se refirió a los esclavos peruanos como: 
"Sujetos al capricho o crueldad de los capataces, el chasquido del látigo y los quejidos... No es extraño que aquellos seres desgraciados pierdan su capacidad intelectual al peso de tan cruel tratamiento y que lleguen a un estado tal de degradación y embrutecimiento que dé razones aparentes a los enemigos de su libertad para presentarlos como indignos e incapaces de gozar de los derechos del hombre" (Miller, 1829: 187).

El tipo de trato recibido y la explotación sistemática e inhumana de los esclavos en el Perú explicarían su condición de servidumbre, sumisión e ignorancia. En ese sentido, resulta esclarecedor el caso que el general narró, sucedido en los enfrentamientos entre realistas y revolucionarios en el Alto Perú, que terminaría con la captura de muchos soldados negros y mulatos del ejército rioplatense, que se volverían esclavos de las haciendas de la costa peruana. Sobre su situación, Miller señaló:

"dispuso que se les diera libertad, y unos treinta de ellos, que fueron los que pudieron encontrarse. Entre estos había dos jóvenes de color, que habían llegado en el servicio patriota a la clase de oficiales, en consecuencia de su buena conducta y bizarría. Pero confinados por espacio de ocho años en galpones, trabajando como bestias de carga, y asociados únicamente con esclavos bajos, sus almas se habían envilecido en la degradante esclavitud, y se entregaron a la bebida y a todos los vicios inseparables a su estado. De tal modo eran ya incorregibles que pudieron ser nuevamente empleados. Así dos hombres de natural bien inclinados y bizarros se perdieron para el servicio, para la sociedad y para ellos mismos" (Miller, 1829: 232)

Claramente el general señala la degradación y opresión de los negros y mulatos en el Perú, afirmando que los habían convertido en seres sin capacidad ni voluntad. Considera que la situación de la plebe en el Perú no sería de esas características si hubieran tenido un mejor trato. En relación, a la participación de la plebe en las guerras de independencia, Miller afirmó: "la revolución de la América del Sur y la de la isla de Santo Domingo han suministrado muchas pruebas convincentes de que la capacidad de los negros no es inferior a la de los blancos; pero cuando se les trata como a bestias de carga, ¿qué puede esperarse de ellos?" (1829: 188). En base a estos testimonios, para el general bonaerense el dominio virreinal ocasionó aquel estado de servidumbre y decadencia de la plebe. Por lo tanto, el ingreso de las fuerzas patriotas debía suponer el rompimiento de esta condición de subordinación y la búsqueda de una mejor posición de los sectores subalternos.

La salida de San Martín del Perú, en modo alguno significó un cambio en la percepción que la elite tenía de los grupos populares. En La Abeja Republicana encontramos un artículo titulado "Diálogo entre la Plebe y los Grandes", en donde se observaba la imagen que tenían las elites criollas de la plebe, y como no los consideraban dentro de los planes políticos del destino del país. A lo largo del texto podemos encontrar la clara diferencia entre unos y otros, defendida por los editores del periódico. Los grupos de poder califican a los sectores populares como plebe, muchedumbre, pueblo rebelde, insolente y medroso. No obstante, la guerra había sido una escuela de aprendizaje e ilustración para los sectores subalternos, erosionando la esclavitud y la servidumbre. Pese a ello, la elite insistía en describir a la plebe como un populacho subordinado y sin capacidad política.4 El periódico El Loro afirmó:

${ }_{4}$ La Abeja Republicana, $\mathrm{N}^{\circ}$ 33, domingo 24 de noviembre de 1822. 
"Las clases ínfimas, como pies del cuerpo social, sufrían el enorme peso de su gran mole. Vasallos propiamente eran los plebeyos; y los nobles realmente señores... Fraguada así la cadena de esclavitud para la América, nada temía el opresor por parte de los nobles, porque los había constituido accionistas del despotismo y tiranía; y mucho menos tenía que recelar del vulgo que en todas partes es incapaz de movimiento propio.” 5

Entonces, para ambos periódicos, la diferencia social era necesaria. Como lo señaló la Abeja, existían "ciudadanos fuertes o débiles, ricos o pobres, grandes o pequeños”, porque era "el origen natural y legítimo de los diversos estados o clases". Igualmente, el periódico afirmaba que "la desigualdad es justa, porque se dirige al bienestar de todos." 6 Incluso, en el congreso constituyente de octubre de 1822, José Faustino Sánchez Carrión afirmaría que la plebe: "no ha nacido sino para servir a los placeres de la elite." 7

A pesar de la proliferación de planteamientos liberales en favor de "educar al soberano", persistieron los temores de la elite frente a una posible revolución popular. Este miedo estaba fundado en algunos excesos cometidos por los sectores populares, como bien señaló el general Álvarez de Arenales: "he nombrado provisionalmente un Alcalde, para que se sujete esta plebe, que a no ser por la moralidad de mis tropas habría avanzado en los crímenes de saqueos y robos" (Dunbar, 1971: 112). En ese mismo tono, Petronila Abeleyra escribió a su esposo, el comandante de guerrillas Francisco de Paula Otero: "alarmaron al pueblo, esparciendo la voz de que los negros andaban saqueando la villa y matando a los que resistían, con esto adujeron todos a las armas" (Dunbar, 1971: 185). Testimonios como estos, evidencian el rol asignado a las fuerzas armadas -sean patriotas o realistas- para controlar los excesos reales o imaginarias del populacho.

Estas percepciones no eran privativas de los militares. El ministro Monteagudo y el periódico El Pacificador del Perú, mantendrían también tenían estas percepciones. Sobre el pueblo, se señala: "ciego acerca de sus intereses, es necesario, aunque sea doloroso, desengañarlo por la fuerza, añadiendo algunos días de estragos a los años de horror en que nos ha precipitado su terquedad." 8

La posición del ejército patriota y el gobierno del protectorado guardaba relación con las acciones violentas cometidas por las tropas, vinculando a la plebe con estos excesos, que consistieron en usurpación de los bienes de diversos pueblos y enrolamiento forzado de nuevos soldados. Aunque botín de guerra, 'ranchería' y leva de tropas era una práctica frecuente en ambos ejércitos. La línea entre legalidad e ilegalidad era violada por los imperativos y necesidades de la guerra. Así, uno de estos casos se dio en Santo Domingo de Chincha, donde Manuel Hernández, personero del pueblo, denunció los daños y perjuicios sufridos por el reclutamiento de jóvenes de su localidad: "Hemos padecido los mayores ultrajes que escandalizan a la razón y los bienes, animales de cría, ganado mayor y menor,

5 El Loro, Lima, $\mathrm{N}^{\circ}$ 5, del miércoles 2 de octubre de 1822.

${ }^{6}$ La Abeja Republicana, Lima, t. 1, No 19, del domingo 6 de octubre de 1822.

7 La Abeja Republicana, Lima, t. 1, $\mathrm{N}^{\circ}$ 25, del domingo 27 de octubre de 1822.

${ }^{8}$ El Pacificador del Perú, Huaura, $\mathrm{N}^{\circ}$ 2, del 20 de abril de 1821. 
cabalgaduras apenadas, napas, dinero, servicio personal de sesenta indios, y otras pensiones, en igual que los granos comestibles y dinero, fueron sin medida objeto de un pillaje." 9

Los abusos de las tropas patriotas fueron un argumento realista para disuadir a las comunidades de apoyar la independencia, bajo la idea de que su situación era mejor con el rey.10 Este discurso realista fue repudiado por la prensa patriota, sindicando de estos desenfrenos a los grupos populares, caracterizándolos como "una plebe desenfrenada y resentida". ${ }^{11}$ Para reforzar esta idea, La Abeja Republicana señalaría en 1822: "jamás el indígena será un obstáculo para la elección de un gobierno sabio, y paternal. Patriota por naturaleza ha procurado siempre, aunque con mal suceso, recobrar la antigua independencia del Perú. Con su continua agitación ha comprobado que el pueblo conquistado permanece constantemente en revolución." ${ }^{12}$ Los periódicos dan cuenta que la plebe, aunque fue proclive a la independencia, no estaba exenta de incurrir en malas prácticas -e incluso delitos- en diversas regiones del Perú.

A pesar de las denuncias de la prensa y sus visiones de la plebe, su participación política y militar queda fuera de toda duda. Por señalar algunos casos, en Iquicha, los indios monarquistas de Huanta se alzaron contra el gobierno republicano entre 1825 y 1828 (Bonilla, 2016; Méndez, 2005). Incluso, en la sublevación del Callao en febrero de 1824, las tropas enardecidas de los regimientos del ejercito patriota apresaron a sus oficiales y entregaron el castillo a las fuerzas realistas, lo que fue una grave amenaza para la consolidación de la independencia (Miller, 1829: 79).

En síntesis, examinando la prensa de la época y diversos testimonios de militares y viajeros, observamos la existencia de una narrativa de parte de la elite, los militares y el gobierno señalando la peligrosidad e ignorancia de la plebe, buscando deslegitimarlos como actores políticos para poder asumir roles gubernamentales con el fin de que no sean una amenaza para los grupos de poder. Igualmente, en los alegatos encontramos el rol que se les asigna en los ejércitos, que no solo habían conseguido la independencia, sino que debían evitar que los sectores subalternos cometan desmanes y excesos y protejan la propiedad privada.

\section{CONCLUSIONES}

La investigación ha mostrado indicios de las características sociales de la plebe y las narrativas políticas construidas por las elites políticas sobre el papel de los sectores populares en las guerras de independencia. La idea central que recorre todo el trabajo es que estos actores fueron imaginados por las elites como una plebe desenfrenada carentes de acción y capacidad política propia, por ello se buscaba persuadir a los sectores subalternos a mantenerse fielmente subordinada al gobierno colonial o republicano. Los temores de la elite

\footnotetext{
9 Archivo General de la Nación-Perú, Campesinado, Derecho Indígena, leg. 37, c. 772, 1821, fs. 8.

${ }^{10}$ El Triunfo de la Nación, Lima, $\mathrm{N}^{\circ} 32$, del viernes 1 de junio de 1821.

${ }^{11}$ Los Andes Libres, Lima, $\mathrm{N}^{\circ}$ 1, del martes 24 de julio de 1821.

${ }^{12}$ La Abeja Republicana, Lima, t. 1, Nº 9, del domingo 1 de septiembre de 1822.
} 
siempre estuvieron relacionados con algún imaginario movimiento organizado por el populacho, y sus intereses opuestos a las urgencias y necesidades de los sectores populares. En ese sentido, consideramos que en el contexto de la conmemoración del bicentenario de la independencia del Perú debe ser una oportunidad para reconocer el rol cumplido por diferentes sectores sociales como indígenas, campesinos y afrodescendientes, que tuvieron una presencia significativa como actores políticos y militares dentro de la independencia peruana.

El estudio desagregado de la composición de los sectores populares y su intervención en la guerra de independencia debe identificar y analizar sus motivaciones en un contexto de crisis no sólo política, sino también económica; reconociendo que estos grupos sociales no fueron una masa pasiva, sin objetivos, dado que numerosas investigaciones han demostrado su activa participación en el proceso fundacional de la Republica peruana.

\section{REFERENCIAS BIBLIOGRÁFICAS}

Aguirre, C. (2005). Breve historia de la esclavitud en el Perú. Una herida que no deja de sangrar. Fondo Editorial del Congreso de la República del Perú.

Aguirre, C. (1993). Agentes de su propia libertad. Los esclavos de Lima y la desintegración de la esclavitud, 1821-1854. PUCP.

Arrelucea, M. (2018). Sobreviviendo a la esclavitud: Negociación y honor en las prácticas cotidianas de los africanos y afrodescendientes, Lima 1970-1820. IEP.

Aljovín, C. y Velázquez M. (eds.). (2017). Las voces de la modernidad: Perú, 1750-1870. Lenguajes de la Independencia y de la República. Fondo Editorial del Congreso de la República del Perú.

Basadre, J. (1973). El azar en la historia y sus límites. Ediciones P. L. V.

Basadre, J. (1929). La multitud, la ciudad y el campo en la historia del Perú. Imprenta A. J. Rivas Berrio.

Bazán, M. (2017). La participación de los sectores populares en la rebelión de Huánuco, 1812: saqueadores, seductores e incanistas. Tesis de magister en Historia, UNMSM.

Beltrán, E. (1977). Las guerrillas de Yauyos en la emancipación del Perú, 1820-1824. Editorial Técnicos Asociados.

Bonilla, H. (ed.). Indios, negros y mestizos en la independencia. Planeta-Universidad Nacional de Colombia.

Bonilla, H. (2016). Metáfora y realidad de la independencia en el Perú. IEP.

Bonilla, H. y Spalding, K. (1972). La independencia en el Perú: la palabra y los hechos. En Bonilla, Chaunu, Halperin, Vilar, Spalding y Hobsbawm. La independencia en el Perú. IEP.

Chambers, S. (2003). De súbditos a ciudadanos: honor, género y política en Arequipa (17801854). Red para el desarrollo de las Ciencias Sociales en el Perú.

Chust, M. y Rosas, C. (eds.). El Perú en Revolución. Independencia y guerra: un proceso, 1780-1826. Publicaciones Universitat Jaume I.

Chust, M. y Serrano, J. (2009). Presentación. Guerras, monarquías e independencia de la América española. Ayer, 74, 13-21. 
Cosamalón, J. (1999). Amistades peligrosas: Matrimonios indígenas y espacios de convivencia interracial (Lima 1795-1820). En O’Phelan, S. (comp.). El Perú en el siglo XVIII. La era borbónica (pp. 349-366). PUCP.

Escanilla, S. (2021). El rol de los sectores indígenas en la independencia del Perú. Bases para una nueva interpretación. Revista de Indias, 81(281), 51-81.

Espinoza, W. (2014). Chachapoyas frente a la independencia política del Perú. Derrama Magisteral.

Espinoza, W. (2007). Reacción de los indígenas de Cajamarca frente a la independencia de Trujillo y Lima. 1821-1822. Investigaciones Sociales, 18.

Flores Galindo, A. (1987). Independencia y clases sociales. En Flores Galindo, A. (comp.). Independencia y revolución, 1780-1840, INC.

Flores Galindo, A. (1984). Aristocracia y plebe: Lima, 176o-183o. Mosca Azul.

Flores Galindo, A. (1983). Soldados y montoneros. En Flores Galindo, A. Buscando un inca: Identidad y utopía en los andes. Sur Casa de Estudios del Socialismo.

Garrett, D. (2009). Sombras del imperio. La nobleza indígena del Cuzco, 1750-1825. IEP.

Guardino, P. (1989). Las guerrillas y la independencia peruana: un ensayo de interpretación. Pasado y Presente, $\mathrm{n}^{\mathrm{O}}$ 2-3.

Hunefeldt, C. (2010). Esclavitud, percepciones raciales y lo político: la población negra en la era independentista en Hispanoamérica. En Bonilla, H. (ed.). Indios, negros y mestizos en la independencia. Grupo Editorial Planeta-Universidad Nacional de Colombia.

Hunefeldt, C. (1979a). Los negros de Lima: 1800-1830. Histórica, 2(2).

Hunefeldt, C. (1979b). Cimarrones, bandoleros y milicianos: 1821. Histórica, 3(2).

Leguía y Martínez. (1921). Los guerrilleros peruanos. En La Prensa, 28 de julio, 1921.

Nieto, V. (2004). Control político, sectores sociales y la revolución de 1812 un estudio de la coyuntura política de Huanuco de fines del periodo colonial. Fondo Editorial Cultura Peruana.

Núñez, E. (ed.). (1971). Relaciones de Viajeros. Colección Documental de la Independencia del Perú. Comisión Nacional del Sesquicentenario de la independencia del Perú, vol. 1.

Marchena, J. (1992). Ejército y milicias en el mundo colonial americano. MAPFRE.

Méndez, C. (1991). Los campesinos, la independencia y la iniciación de la república. El caso de los iquichanos realistas: Ayacucho 1825-1828. En Urbano, H. (comp.) y Lauer, M. (ed). Poder y violencia en los Andes. Centro Bartolomé de Las Casas.

Méndez, C. (2005). The Plebeian Republic. The Huanta rebellion and the making of the Peruvian state, 1820-1850. Duke University Press.

Miller, Guillermo. (1975) [1829]. Memorias del General Guillermo Miller. Editorial Arica S.A.

Montoya, G. (2020). La independencia controlada. Guerra, gobierno y revolución en los andes. Sequilao Editores.

Montoya, G. (2002). La independencia del Perú y el fantasma de la revolución. IEP-IFEA.

Morán, D. (2020). El mundo de la plebe. La participación popular en la independencia del Perú (una aproximación historiográfica). En CHUST, Manuel (ed.). 1821. México vs Perú. Editorial Sílex.

Morán, D. y Aguirre, M. (2013). La plebe en armas. La participación popular en las guerras de independencia. Fondo Editorial de la Universidad Peruana Simón Bolívar. 
"VASALLOS PROPIAMENTE ERAN LOS PLEBEYOS; Y LOS NOBLES REALMENTE SEÑORES". LA PARTICIPACIÓN POPULAR DURANTE LA INDEPENDENCIA EN EL PERÚ, 1821-1824

ISSN: 2710-0499 ISSN-L: 2710-0480

Morán, D. y Carcelén, C. (eds.). (2019). Las guerras de independencia entre dos fuegos. Cambios y permanencias. Fondo Editorial de la Universidad Nacional de Trujillo.

Morán, D. y Carcelén, C. (eds.). (2018). Las guerras de independencia en clave bicentenario. Problemas y posibilidades. Grupo Gráfico del Piero.

O 'Phelan, S. (ed.). 1814: La junta de gobierno del Cuzco y el sur andino. IFEA-PUCPFundación Bustamante de la Fuente.

O 'Phelan, S. (2012). Un siglo de rebeliones anticoloniales. Perú y Bolivia 170o-1783. IFEAIEP.

O 'Phelan, S. (1987). El mito de la independencia concedida: los programas políticos del siglo XVIII y del temprano XIX en el Perú y el Alto Perú (1730-1814). En Flores Galindo, A. (comp.). Independencia y revolución, 1780-1840. INC.

Pilco, N. (2021). Puno durante la Independencia (1809-1825). Universidad Nacional del Altiplano.

Porras, R. (1974). Los ideólogos de la emancipación. Editorial Milla Batres.

Puente Candamo, J. (1970). Notas sobre las causas de la independencia del Perú. Librería Studium.

Rivera, R. (1958). Los guerrilleros del centro en la emancipación peruana. Talleres Gráficos P. L. Villanueva.

Rojas, R. (2017). La república imaginada: representaciones culturales y discursos políticos en la época de la independencia. IEP.

Sala i Vila, N. (1996). Y se armó el tote tole. Tributo indígena y movimientos sociales en el virreinato del Perú, 1784-1814. IER José María Arguedas.

Sala i Vila, N. (1992). La Constitución de Cádiz y su impacto en el gobierno de las comunidades indígenas en el virreinato del Perú. Boletín Americanista, $\mathrm{n}^{0} 42-43$.

Sánchez, S. (2011). Norte y sur: Las milicias de Arequipa y Trujillo y la construcción de las diferencias regionales en el Perú (1780-1815). En Mazzeo, C. (ed.). Las relaciones de poder en el Perú. Estado, regiones e identidades locales, siglo XVII-XIX. PUCP.

Temple, E. (1971). La acción patriótica del pueblo en la emancipación. Guerrillas y montoneras. Colección Documental de la Independencia del Perú. Comisión Nacional del Sesquicentenario de la independencia del Perú, vol. 1.

Thurner, M. (2006). Republicanos Andinos. CBC-IEP.

Velásquez, D. (2017). La guerra de opinión y el vocabulario político de los plebeyos durante las guerras de independencia del Perú. En Chust, M. y Rosas, C. (eds.). El Perú en Revolución. Independencia y guerra: un proceso, 1780-1826. Publicaciones Universitat Jaume I, 297-312.

Vergara, G. (1973). Montoneras y guerrillas en la etapa de la emancipación del Perú, 182O1825. Imprenta Salesiana.

Walker, C. (1999). De Túpac Amaru a Gamarra. Cuzco y la formación del Perú republicano, 1780-1840. Centro Bartolomé de Las Casas.

Walker, C. (2009). El crimen en la época del gran miedo: Los indios y el Estado en el sur andino, 1780-1820. En Walker, C. Diálogos con el Perú. Ensayos de historia. Fondo Editorial del Pedagógico San Marcos 